\title{
The new oral anticoagulants in atrial fibrillation: an update
}

\author{
F. W. A. Verheugt
}

Published online: 26 September 2013

(C) The Author(s) 2013. This article is published with open access at Springerlink.com

\begin{abstract}
In patients with nonvalvular atrial fibrillation, oral anticoagulation with the vitamin $\mathrm{K}$ antagonists acenocoumarol, phenprocoumon and warfarin reduces the risk of stroke by more than $60 \%$, whereas single or double antiplatelet therapy is much less effective and sometimes associated with a similar bleeding risk as vitamin $\mathrm{K}$ antagonists. Besides bleeding, and intracranial haemorrhage in particular, INR monitoring remains the largest drawback of vitamin $\mathrm{K}$ antagonists. In the last decade oral agents have been developed that directly block the activity of thrombin (factor IIa), as well as drugs that directly inhibit activated factor $\mathrm{X}(\mathrm{Xa})$, which is the first compound in the final common pathway to the activation of thrombin. These agents have been approved for stroke prevention in atrial fibrillation and are now reimbursed under a national guideline for their safe use. They have advantages in that they do not need monitoring and have a fast onset and offset of action, but lack an established specific antidote. This survey addresses the role of modern anticoagulation for stroke prevention in atrial fibrillation.
\end{abstract}

Keywords Atrial fibrillation · Stroke · Prevention · Warfarin · Dabigatran $\cdot$ Rivaroxaban $\cdot$ Apixaban

The yearly incidence of stroke in patients with atrial fibrillation is about $5 \%$ [1], which is 5 times higher than in comparable populations in sinus rhythm. The stroke risk largely depends on the underlying heart disease. In 'lone' atrial fibrillation (absence of heart disease) the stroke risk is only $0.5 \%$ per year [2], whereas in atrial fibrillation associated with rheumatic valvular heart disease, such as mitral valve stenosis,

F. W. A. Verheugt ( $\bowtie)$

Heartcenter, Department of Cardiology, Onze Lieve Vrouwe

Gasthuis (OLVG), Oosterpark 9, 1091 AC Amsterdam, the Netherlands

e-mail: f.w.a.verheugt@olvg.nl it is very high. Also in other heart diseases when atrial fibrillation is absent, such as congestive heart failure, the stroke risk is elevated [3].

\section{The classical anticoagulants}

The coagulation cascade is a complex system, which can be activated by an intrinsic pathway (blood stasis and contact activation) or an extrinsic pathway (exposed tissue after vascular damage). The final common pathway from these two potential stimuli starts with the activation of plasma factor $\mathrm{X}$ into activated factor Xa (Fig. 1). Through activation of factor $\mathrm{V}$, factor II (prothrombin) is activated to thrombin, the aggressive compound splitting fibrinogen into fibrin, which is the matrix of blood clots. The coagulation system is a real cascade. One molecule of factor Xa induces the formation of 50 thrombin molecules. Factor Xa and thrombin are counteracted by the naturally occurring antithrombin-III.

Until recently, the only available oral anticoagulants were the coumarin derivatives. These compounds block the vitamin $\mathrm{K}$ dependent liver production of the plasma coagulation factors II, VII, IX and X. They are usually called vitamin K antagonists and have a relatively narrow therapeutic window, which is due to dose response, food and genetic variation. Therefore, vitamin $\mathrm{K}$ antagonists require close monitoring: overdosing may result in life-threatening bleeding and underdosing in inefficacy. An international and uniform laboratory standard of the intensity of anticoagulation has been introduced: the International Normalised Ratio (INR) replacing the non-standardised prothrombin time and Quick tests. Nevertheless, monitoring remains cumbersome and less than two-thirds of patients on chronic vitamin K antagonist therapy are within the therapeutic window.

Warfarin therapy is the cornerstone in the prevention of thromboembolism in patients with atrial fibrillation. Stroke in 
Fig. 1 Simplified diagram showing the coagulation cascade extrinsic pathway

intrinsic pathway

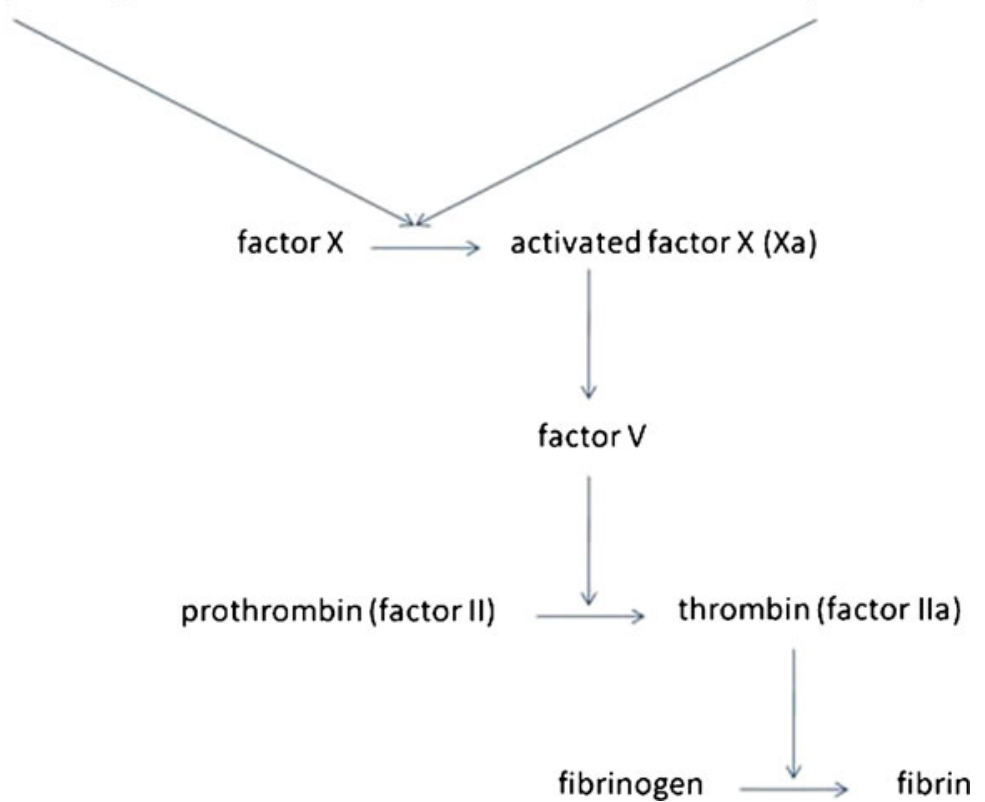

patients with persistent or permanent non-valvular atrial fibrillation can be reduced by $67 \%$ by the use of oral anticoagulants [4]. Severe bleeding with warfarin is seen in 1 out of 100 patients per year, which is double the risk of stroke in lone atrial fibrillation. Therefore, anticoagulation is only indicated in atrial fibrillation patients with a stroke risk that exceeds the risk of severe bleeding. Risk stratification for stroke in atrial fibrillation is now widely accepted with the $\mathrm{CHA}_{2} \mathrm{DS}_{2}$ VASc score [5], where patients with a score of 1 and higher are candidates for oral anticoagulation (Table 1). In atrial fibrillation also the presence of aortic plaque is associated with an elevated stroke risk [6]. The optimal target INR for patients on vitamin $\mathrm{K}$ antagonists is between 2.0 and 3.0 [7]. In the Netherlands a higher target INR is advised, but this has never been confirmed to be more effective and/or safer in atrial fibrillation than the internationally accepted target range. In selected patients with atrial fibrillation, vitamin $\mathrm{K}$ antagonists have to be interrupted

Table $1 \mathrm{CHA}_{2} \mathrm{DS}_{2}$ VASc score points for prediction of stroke in atrial fibrillation [5]

\begin{tabular}{ll}
\hline Risk factor & Points \\
\hline Age 65-75 years & 1 \\
Age over 75 years & 2 \\
Female gender & 1 \\
Coronary or peripheral artery disease & 1 \\
Previous stroke & 2 \\
Hypertension & 1 \\
Symptoms or signs of left ventricular dysfunction & 1 \\
Diabetes mellitus & 1 \\
\hline
\end{tabular}

for surgical procedures, but in those undergoing pulmonary vein isolation they can be continued [8].

Yet, the use of vitamin $\mathrm{K}$ antagonists is associated with the risk of severe and even fatal bleeding. Many physicians are reluctant to prescribe warfarin to the elderly patient with atrial fibrillation because of the risk of bleeding, and many are convinced that aspirin is a wise and acceptable alternative. However, there are now reassuring comparative data in the very elderly (over 75 years) showing superiority of warfarin over aspirin with equal bleeding risk for both therapies [9]. This is one of the reasons antiplatelet therapy is now discouraged in stroke prevention in the European guidelines [5].

\section{The new oral anticoagulants}

In the past decade several oral direct inhibitors of thrombin and of factor Xa have been developed (Table 2). They proved to be specific antagonists and show a dose-efficacy relationship. A major advantage is that there does not seem to be any drug tolerance and food interaction, and monitoring is not needed with these agents. They have a fast onset of activity and a relatively short duration of action, which in case of bleeding or planned surgery is another advantage over vitamin $\mathrm{K}$ antagonists. On the other hand, some agents need twice daily dosing and the fast offset of action may be problematic in case of poor compliance, e.g. when the patient does not take 2 or 3 doses in sequence. This disadvantage is not seen with warfarin, which has a very slow offset of action. Furthermore, an antidote algorithm for the novel oral anticoagulants has not been developed yet, while this is well established for warfarin. 
Table 2 The new oral anticoagulants

II a activated factor II (thrombin), $X a$ activated factor $\mathrm{X}, T \frac{1}{2}(h)$ plasma half-life (hours), b.i.d. twice daily, $q d$ once daily

${ }^{a}$ not yet approved

\begin{tabular}{lllll}
\hline Class & Name & T $1 / 2(\mathrm{~h})$ & Dosing & Excretion \\
\hline Anti-IIa (antithrombin) & Dabigatran $\left(\right.$ Pradaxa $\left.^{\mathrm{R}}\right)$ & $7-9$ & b.i.d. & $80 \%$ kidney, 20\% liver \\
Anti-Xa & Apixaban $\left(\right.$ Eliquis $\left.^{\mathrm{R}}\right)$ & $8-15$ & b.i.d. & $21 \%$ kidney, $78 \%$ liver \\
& \left.${\text { Rivaroxaban }\left(\text { Xarelto }^{\mathrm{R}}\right)}\right)$ & $9-12$ & qd & $33 \%$ kidney, 66 \% liver \\
& Edoxaban $\left(\text { Lixiana }^{\mathrm{R}}\right)^{\mathrm{a}}$ & $8-10$ & qd & $35 \%$ kidney, 65\% liver \\
\hline
\end{tabular}

The advantages and disadvantages of the novel oral anticoagulants relative to vitamin $\mathrm{K}$ antagonists are summarised in Table 3.

\section{The trials and registries}

In atrial fibrillation the direct oral thrombin (factor IIa) inhibitor ximelagatran is as effective as warfarin and reduces major bleeding $[10,11]$, but the drug is associated with liver toxicity, which withholds its approval and further marketing. Another direct oral thrombin blocker, dabigatran, has been evaluated in comparison with warfarin in the huge phase III RE-LY trial in atrial fibrillation [12]. Finally, oral direct factor Xa blockers have become available and are effective in the prevention and treatment of deep vein thrombosis and pulmonary embolism [13-18]. Rivaroxaban, apixaban and edoxaban have been tested for stroke prevention in atrial fibrillation (Table 4) $[19,20]$. Except for edoxaban, where results will be available shortly, they show better or equal efficacy compared with warfarin at no excess bleeding [12, 19, 20]. As shown in Table 4, the trials differ in design in that RE-LY is open label and the other double blind, by which INR is measured at the point of care and sham INRs are computer-generated for the patients randomised to the new agent. Double-blind controlled trials are the highest standard of quality in evidence-based medicine and also in the case of INR monitored trials blinding is feasible and successful [11]. Open-label studies have the serious shortcoming of treatment bias. In case of bleeding with open-label warfarin, physicians will react differently than with bleeding with a drug that could be either an experimental short-acting new oral anticoagulant or warfarin. Therefore, the design of RE-LY makes its outcome on softer endpoints doubtful. A good example of this is the differential results of the studies where ximelagatran was compared with warfarin in stroke prevention for atrial fibrillation. SPORTIF-III was an open-label trial and stroke prevention tended to be better with ximelagatran than with warfarin [10], but in SPORTIF-V with its double-blind design it was the other way around [11]. The ximelagatran arms of both trials had an almost identical outcome making both studies highly comparable in baseline features. Although complex to perform, trials of the new oral anticoagulants had to be double-blind in design. The trials in evidence-based medicine we use nowadays were tested double-blind in the 1990s, such as those on beta blockers, aspirin, statins and ACE inhibitors.

By design, the trials included both warfarin-experienced and warfarin-naive patients and by stratification the results

Table 3 Advantages and disadvantages of the new oral anticoagulants relative to warfarin

\begin{tabular}{|c|c|c|}
\hline Class & Advantages & Disadvantages \\
\hline \multirow[t]{6}{*}{ Oral direct IIa/Xa blockers } & More effective against thromboembolism than VKA & No monitoring in case of bleeding or urgent surgery \\
\hline & Fast onset of action & Not applicable in severe renal failure $(\mathrm{CrCl}<30 \mathrm{ml} / \mathrm{min})$ \\
\hline & Fast offset of action (in case of bleeding/surgery) & Not applicable in carriers of artificial heart valves \\
\hline & $\begin{array}{l}\text { Better safety, especially less intracranial bleeding than } \\
\text { VKA }\end{array}$ & Short duration of action (thrombosis risk with poor compliance \\
\hline & Ease (no monitoring) & Antidote strategy not established \\
\hline & & Some agents have interaction with anti-arrhythmic agents \\
\hline \multirow[t]{5}{*}{ Vitamin $\mathrm{K}$ antagonists } & Therapeutic window established & Monitoring of INR \\
\hline & Antidote algorithm established & Drug interaction with many agents \\
\hline & Long duration of action & Food interaction \\
\hline & (low thrombosis risk with poor compliance) & Slow onset of action \\
\hline & & High bleeding risk, intracranial bleeding in particular \\
\hline
\end{tabular}

$V K A$ vitamin $\mathrm{K}$ antagonists, II $a$ activated factor II (thrombin), Xa activated factor $\mathrm{X}$ 
Table 4 Phase III trials with new oral anticoagulants in atrial fibrillation

\begin{tabular}{|c|c|c|c|c|c|}
\hline Class & Name & Comparator & Design & $n$ & Trial \\
\hline Anti-IIa (antithrombin) & Dabigatran & Warfarin (clinic) & Open & 18,133 & RE-LY [12] \\
\hline \multirow[t]{3}{*}{ Anti-Xa } & Apixaban & Warfarin (point of care) & Double-blind & 14,264 & ROCKET-AF [19] \\
\hline & Rivaroxaban & Warfarin (point of care) & Double-blind & 18,201 & ARISTOTLEF [20] \\
\hline & Edoxaban & Warfarin (point of care) & Double-blind & $>21,000$ & ENGAGE AF TIMI-48 \\
\hline
\end{tabular}

II $a$ activated factor II (thrombin), Xa activated factor X, $n$ number of patients

${ }^{\mathrm{a}}$ to be presented late 2013

on both efficacy and bleeding proved similar in the three trials. This suggests that newcomers with atrial fibrillation benefit from the new drugs as well as those who have been switched from warfarin to the new strategy. However, these are post-hoc analyses, which have been heavily criticised in this kind of trial in atrial fibrillation, such as the ACTIVE-W study [21].

Finally, until recently there were no data on the long-term safety and efficacy of the new drugs. But, recently, a more than 4-year follow-up study of about half of the patients on both doses of dabigatran in the RE-LY trial, who continued the drug, was published [22]. It showed acceptable gastrointestinal bleeding and stroke data, but this was a highly selected population without a control group, which does not definitively confirm dabigatran's safety [23]. On the other hand, a mini-sentinel analysis by the Food and Drug Administration in the US also showed a favourable safety profile of dabigatran when compared with warfarin [24]. In five trials of controlled studies with dabigatran in the prevention and treatment of thrombosis, fatal bleeding was lower than with warfarin [25], which confirmed another meta-analysis of all new agents versus warfarin [26]. Although there is still no effective specific antidote for the new drugs, these data make the development of such an antidote less urgent. Unspecific regimens such as prothrombin concentrate complex $\left(\mathrm{Cofact}^{\mathrm{R}}\right)$ seem to be a reasonable alternative for the inactivation of the
Xa blocker rivaroxaban, but not the IIa blocker dabigatran, but this has only been tested in young healthy volunteers [27].

\section{Introduction of the new oral anticoagulants}

It took quite a while in the Netherlands before the new agents became eligible for reimbursement after approval for their use in atrial fibrillation [28], when compared with other regions in the EU and in the rest of the world. The reimbursement will not affect the cardiology budgets. The government produced a report about appropriate use [29] and the national society of medical specialists published a broadly based guideline for safe utilisation [30] of the new oral anticoagulants for the various indications. Not general practitioners, but only medical specialists such as cardiologists, orthopaedic surgeons, neurologists and internists are allowed to prescribe the agents. Finally, major and life-threatening bleeding must be reported according to the Lareb Intensive Monitoring Program (www. lareb.nl). The checklist derived from the national guideline is summarised in Table 5.

Recently, the European Heart Rhythm Association published a very useful and more extensive practical guide on the use of the new agents in atrial fibrillation [31]. In this paper also drug interactions are described more in detail as well as what to do with cardioversion and with patients suffering from
Table 5 Checklist for safe use of the new oral anticoagulants [26]

$V K A$ vitamin $\mathrm{K}$ antagonist, INR International Normalised Ratio, $N O A C$ new oral anticoagulant

\begin{tabular}{ll}
\hline Organisation & A local protocol for handling of bleeding and/or surgery must be written \\
Prescription & Fill out the doctor's statement and explain transition if the patient is on VKA \\
Renal function & Creatinine clearance should be more than $30 \mathrm{ml} / \mathrm{min}$ \\
Transition & Stop VKA and wait for the INR to be $<2.0$ before starting NOAC \\
Elective major procedure & Stop NOAC $24-48$ h ahead according to renal function, no bridging \\
Elective minor procedure & Consider NOAC continuation \\
Minor bleeding & Consider NOAC continuation \\
Moderate bleeding & Skip one NOAC dose and perform haemostasis \\
Major bleeding & Stop NOAC, perform haemostasis and consider Cofact ${ }^{\mathrm{R}}$ and/or Cyclokapron ${ }^{\mathrm{R}}$ \\
Life-threatening bleeding & All of the above and consider Novoseven \\
Reporting of bleeding & Severe bleeding must be reported to Lareb Monitoring Program (www.lareb.nl) \\
\hline
\end{tabular}


comorbidities: coronary artery disease treated with or without revascularisation, acute stroke and cancer.

\section{Conclusion}

From the current trials it has become clear that oral direct inhibition of the major haemostatic proteins factor IIa or factor $\mathrm{Xa}$ is at least as effective as warfarin in stroke prevention of atrial fibrillation with a safety profile which is far more favourable than warfarin, especially where intracranial bleeding is concerned. The lack of monitoring will be the major reason for many physicians to switch from warfarin to the new agents and to put newcomers with atrial fibrillation without anticoagulants on them right away.

The current absence of an antidote has not led to catastrophic bleeding in the trials and the recent registries. The only significant clinical drawback is that the new agents cannot be used in patients with severe renal failure and in those with artificial heart valves.

Conflict of interest I have received departmental research funding and consultancy fees from BMS/Pfizer and Bayer Healthcare as well as speaker honoraria from Bayer Healthcare, Boehringer-Ingelheim, BMS/ Pfizer and Daiichi Sankyo

Open Access This article is distributed under the terms of the Creative Commons Attribution License which permits any use, distribution, and reproduction in any medium, provided the original author(s) and the source are credited.

\section{References}

1. Wolf PA, Abbott RD, Kannel WB. Atrial fibrillation: a major contributor to stroke. The Framingham study. Arch Intern Med. 1987;147:1561-4.

2. Kopecky SL, Gersh BJ, McGoon MD, et al. The natural history of lone atrial fibrillation: a population-based study over three decades. N Engl J Med. 1987;317:669-74.

3. Verheugt FWA. Antithrombotic therapy in heart failure. Neth Heart J. 2012;20:176-8.

4. Lip GY, Hart RG, Conway DS. Antithrombotic therapy for atrial fibrillation. BMJ. 2002;325:1022-5.

5. Camm AJ, Lip GY, De Caterina R, et al. 2012 focused update of the ESC guidelines for the management of atrial fibrillation. Eur Heart J. 2012;31:2369-429.

6. Dinh T, Baur LH, Pisters R, et al. Feasibility of TEE-guided stroke risk assessment in atrial fibrillation-background, aims, design and baseline data of the TIARA pilot study. Neth Heart J. 2011;19:214-22.

7. De Caterina R, Husted S, Wallentin, et al. Anticoagulants in heart disease: current status and perspectives of new oral anticoagulants. $\mathrm{J}$ Am Coll Cardiol. 2012;59:1413-25.

8. Oude Velthuis B, Stevenhagen J, van Opstal JM, et al. Continuation of vitamin $\mathrm{K}$ antagonists as acceptable anticoagulation regimen in patients undergoing pulmonary vein isolation. Neth Heart J. 2012;20:12-5.

9. Mant J, Hobbs R, Fletcher K, et al. Warfarin versus aspirin for stroke prevention in an elderly community population with atrial fibrillation (the Birmingham Atrial Fibrillation Treatment of the Aged Study, BAFTA): a randomised controlled trial. Lancet. 2007;370:493-503.

10. SPORTIF-III Investigators. Ximelagatran versus warfarin for stroke prevention in patients with nonvalvular atrial fibrillation (SPORTIFIII): randomised controlled trial. Lancet. 2003;362:1691-8.

11. Albers GW, Diener HC, Frison L, et al. Ximelagatran vs warfarin for stroke prevention in patients with nonvalvular atrial fibrillation: a randomized trial. JAMA. 2005;293:690-8.

12. Connolly SJ, Ezekowitz MD, Yusuf S, et al. Dabigatran versus warfarin in patients with atrial fibrillation. N Engl J Med. 2009;361:1139-51.

13. EINSTEIN investigators. Oral rivaroxaban for symptomatic venous thromboembolism. N Engl J Med. 2010;363:2499-510.

14. EINSTEIN-PE investigators. Oral rivaroxaban for the treatment of symptomatic pulmonary embolism. N Engl J Med. 2012;366:1287-97.

15. Eriksson BI, Borris LC, Friedman RJ, et al. Rivaroxaban versus enoxaparin for thromboprophylaxis after hip arthroplasty. N Engl J Med. 2008;358:2765-75.

16. Kakkar AK, Brenner B, Dahl OE, et al. Extended duration rivaroxaban versus short-term enoxaparin for the prevention of venous thromboembolism after total hip arthroplasty: a double-blind, randomized controlled trial. Lancet. 2008;372:31-29.

17. Lassen MR, Ageno W, Borris LC, et al. Rivaroxaban versus enoxaparin for thromboprophylaxis after total knee arthroplasty. N Engl J Med. 2008;358:2776-86.

18. Turpie AGG, Lassen MR, Davidson BL, et al. Rivaroxaban versus enoxaparin for thromboprophylaxis after total knee arthroplasty (RECORD-4). Lancet. 2009;373:1673-80.

19. Patel MR, Mahaffey KW, Garg J, et al. Rivaroxaban versus warfarin in nonvalvular atrial fibrillation. N Engl J Med. 2011;365:883-91.

20. Granger GB, Alexander JH, McMurray JJV, et al. Apixaban versus warfarin in patients with atrial fibrillation. N Engl J Med. 2011;365: 981-92.

21. Verheugt FWA. Good old warfarin for stroke prevention in atrial fibrillation. Lancet. 2006;367:1877-8.

22. Connolly SJ, Wallentin L, Ezekowitz MD, et al. The long term multicenter observational study of dabigatran treatment in patients with atrial fibrillation (RELY-ABLE) study. Circulation. 2013;128:237-43.

23. Verheugt FWA. The new oral anticoagulants in atrial fibrillation forever? Circulation. 2013;128:200-2.

24. Southworth MR, Reichmann ME, Unger EF. Dabigatran and postmarketing reports of bleeding. N Engl J Med. 2013;368:1272-4.

25. Majeed A. Management and outcomes of major bleeding on dabigatran or warfarin. Presented 54th Annual Meeting American Society of Hematology, Atlanta, Dec 8-11, 2012 (https://ash.confex. com/ash/2012/webprogram/Paper49489.html).

26. Anand SS, McDuffie JR, Ortel TL, et al. Comparative effectiveness of warfarin and new oral anticoagulants for the management of atrial fibrillation and venous thromboembolism: a systematic review. Ann Intern Med. 2012;157:796-807.

27. Eerenberg ES, Kamphuisen PW, Sijpkens MK, et al. Reversal of rivaroxaban and dabigatran by prothrombin complex concentrate: a randomized, placebo-controlled, crossover study in healthy subjects. Circulation. 2011;124:1573-9.

28. Verheugt FWA. New antithrombotic agents in atrial fibrillation. Ned Tijdschr Geneeskd. 2011;155:A2143.

29. Gezondheidsraad. Rapport Nieuwe antistollingsmiddelen: een gedoseerde introductie: (http://www.gezondheidsraad.nl/nl/ adviezen/optimale-gezondheidszorg/nieuwe-antistollingsmiddeleneen-gedoseerde-introductie).

30. Orde Medische Specialisten. Leidraad voor zorgvuldige introductie nieuwe antistollingsmiddelen. (http://www.orde.nl/over-oms/nieuws/ leidraad-voor-zorgvuldige-introductie-nieuwe-antistollingsmiddel.html).

31. Heidbuchel H, Verhamme P, Alings M, et al. European Heart Rhythm Association practical guide on the use of the new oral anticoagulants in patients with nonvalvular atrial fibrillation: executive summary. Eur Heart J. 2013;32:2094-106. 